\title{
APPLICATION OF LEAN APPROACHES AND TECHNIQUES IN AN AUTOMOTIVE COMPANY
}

\author{
${ }^{1}$ L. Reis, ${ }^{2}$ M. L. R. Varela, ${ }^{3}$ J. M. Machado, ${ }^{4}$ J. Trojanowska \\ ${ }^{1,2}$ Department of Production and Systems, ${ }^{3}$ Department of Mechanical Engineering, \\ School of Engineering, University of Minho, Guimarães, Portugal \\ ${ }^{4}$ Chair of Management and Production Engineering, Poznan University of Technology, Poland \\ leandro.reis62195@gmail.com, leonilde@dps.uminho.pt,jmachado@dem.uminho.pt,
}

\begin{abstract}
In this paper are applied lean approaches and techniques in an industrial environment at Preh Portugal, Lda., a Company involved in the automotive sector located in Trofa, Portugal. This work makes use of the action-research methodology, aiming to diagnose the production system and to implement lean production procedures in order to optimize the Mizusumashi that supplies several production sections, about plastic Injection, cutting and painting. The results obtained enabled to obtain significant improvements on this Company at several factory management and operational levels.
\end{abstract}

Keywords: lean manufacturing automotive.

\section{Introduction}

The increase on technological changes and the globalization of emerging markets has increased competition worldwide, leading manufacturers to face unprecedented pressure levels.

In order to provide a contribution for facing the actual high levels of competition faced, on an automotive factory studied on this work, some lean approaches and techniques are analyzed and its implementation on the factory proposed.

For an appropriate contextualization of the main subjects underlying this work, a brief literature review about main lean concepts and techniques is presented in this paper. Therefore, a resume about lean production methodology, is presented, according its origins, its principles, and main benefits of its implementation as well as some of its main tools, which include Just-inTime, Kaizen, Standard Work, and Visual Management approaches.

A diagnostic phase including a general description of the Company's productive system, is also presented, along its main production sections involved on this study. Particular emphasis is given to the description of the existing material flow among them, and a more specific description and a critical analysis of Mizusumashi's performance.

Mizusumashi in Japanese (call also water spider) is a person who has a prescribed set of tasks to keep materials in stock at the point of use in production areas. In the other words Mizusumashi is someone who moves quickly and efficiently from place to place to collect and deliver material to the primary members of a flow cell. The main goal of using this solution is to move the non value added work away from the primary works and give all this non value added work to do by Mizusumashi. Mizusumashi are used for improving the delivery of the value through improved efficiency of the primary worker.

Based on the observation of the main behaviour of the existing production scenarios and on the sequential and spaghetti diagrams performed, it was possible to identify the main problems existing on the main production sections analyzed.

Some main contributions for improving the identified problems are described, and some main results presented and analysed.

In order to accomplish this main aims of this paper, it is organized as follows. First, a brief description of the Company and of its main problems is presented. Next, a summarized view over lean principles and approaches is shown. After, a problems analysis and discussion of proposed improvements is presented. Finally, there are presented some conclusions and further work intensions.

\section{Literature review on lean production}

"The kaizen philosophy assumes that our way of life - either being our working life, our social life, or our home life - it should focus on constant improvement efforts." (Imai, 2012). In the centre of the philosophy of continuous improvement is the PDCA (Plan, Do, Check, and Act), a simple and powerful tool introduced in Japan in 1950 by W. Edwards Deming (Pinto, 2008). The purpose of each element that composes this -cycle (Figure 1) is presented below (Van Scyoc, 2008):

- Plan: collect and analyze information, ideas and suggestions and select best improvement plan;

- Do: implement the selected plan;

- Check: collect information and verify if the results planned were reached;

- Act: keep maintaining the implemented plan and if necessary implement corrective actions. 


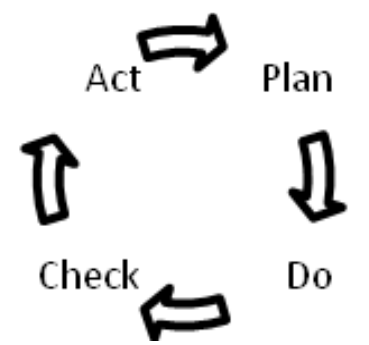

Figure 1: PDCA cycle (Van Scyoc, 2008)

Later, Toyota added the words "go and see" inside the PDCA cycle (Figure 2). This increase resulted from the belief of the company that no matter the level of existing trust, it is always essential to "go and see" personally the state on which the situation is currently undergoing, to understand it truly scenario (Rother, 2009).

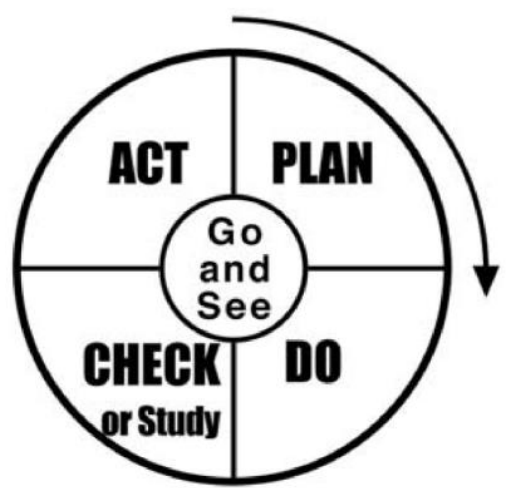

Figure 2: Toyota added the words "Go and See" to the PDCA cycle (adapted from Rother, 2009)

Generally referred as the Toyota Production System (TPS) house, it relies on creating ideal conditions for maintaining a continuous production flow, reduced inventory levels and increased consistency and stability of the process (Pinto, 2008).

He Cho, president of Toyota Motor Corporation, said the following about this TPS house principle (Liker, 2004): "In general, when you try to apply the TPS, the first thing you have to do is to level the production. This is the primary responsibility of production control or production management in general, under the scope of TPS principles. Leveling the production schedule may require some front-loading of shipments or postponing of shipments and it may be necessary to ask some customers if they may be able to wait for a short period of time for their production orders. Once the production level is more or less the same or constant for a month, you will be able to apply pull systems and balance the assembly line."

According Liff and Posey (2004), visual management is a system that promotes organizational improvement and can be used in any Company that seeks to improve its performance, while focusing attention on what is really important.

By using graphical visualization techniques a Company may be able to increase its focus on the improvement of its performance. The information underlying these kind of system should be kept in a timely basis and be easy to understand, in order to help everyone to manage and improve the processes. The triangle of visual management, based on shared knowledge and responsibility (Hines et al., 2011) is presented in Figure 3.

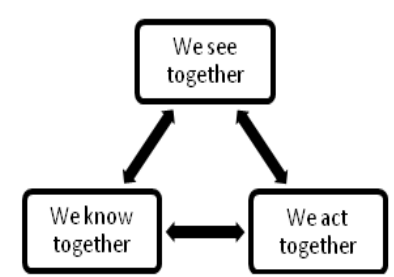

Figure 3: Triangle of Visual Management (adapted from Dennis, 2005)

\section{Lean Production}

According to Womack, Jones and Roos (1990), the term "Lean Production" (LP) was originally introduced by John Krafcik - researcher of the International Motor Vehicle Program (IMVP) - as a way of referring to the production system of Toyota, which when compared with traditional or mass production strategies, enables to reach half of the human effort, half of the space for production, half of the investment in tooling and half of the hours required to develop a new product. Furthermore, it still requires less than half the inventory level, resulting in fewer defects and higher production levels and increasing variety of products, thereby turning a system "lean".

In this context of lean production are combined advantages of small-scale production and mass production, while avoiding the high costs of the first and the rigidity of the second (Womack et al., 1990). It is based on the continuous removal of the activities that does not add value throughout all production areas (Alavi, 2003).

For Warnecke and Huser (1995) this concept can best be characterized as a system of measures and methods that when taken together own the potential to produce a lean state and therefore being particularly competitive, not just in the production context, but throughout a whole Company or an entire supply chain.

Kerper (2006) define LP as: “A systematic approach to identify and eliminate waste (non-value-added activities) through continuous improvement, by flowing the product at the pull of the customer in pursuit of perfection".

\section{Lean Principles}

According to Womack and Jones (2003), this philosophy is the "antidote to waste", providing ways to specify what is meant by value, starting the value of creating actions in the best sequence, and performing these activities without interruption, whenever someone requests it, in an effective way. Thus, the authors identified the following principles associated with this philosophy in mind: value, value chain, flow, pull (pulling) and perfection (Figure 4). 


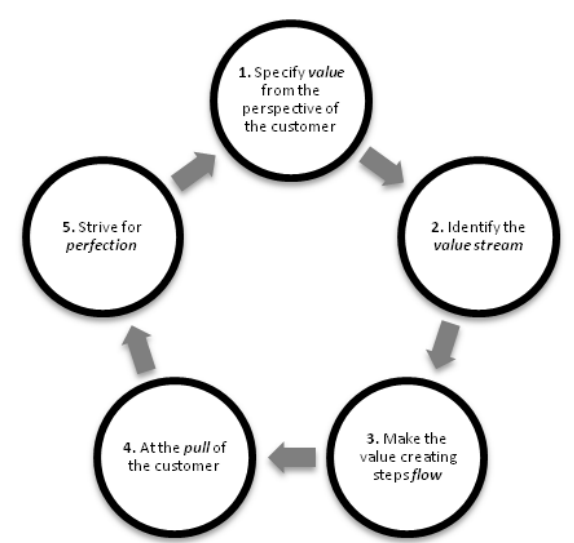

Figure 4: The five principles of lean thinking (adapted from Hines et al., 2011)

"Make those actions that create value flow without interruption, backflows, waiting or scrap." (Hines et al., 2011).
"The more inventory a company has, (...) the less likely it will have what it needs." Taiichi Ohno, referred by Liker (2004).

"Perfection is like infinity. Trying to envision it (and to get there) is actually impossible, but the effort to do so provides inspiration and direction essentially to making progress along the path." (Womack \& Jones, 2003). Spaghetti diagrams

A spaghetti diagram (Figure 5) is a graphical representation of the movements of materials or people along the value chain (Sayer \& Williams, 2007; Womack \& Jones, 2003).

Its use allows the identification of starts, stops and the distances traveled by the object under examination, enabling reduction of unproductive times (Chalice, 2007). In addition to these points, this diagram is still able to highlight critical aspects in a layout, including unoccupied spaces and obsolete ones, inadequate positioning of tools, devices and stations, and waste in the movements of workers (Di Pietro, Mugion, \& Renzi, 2013).

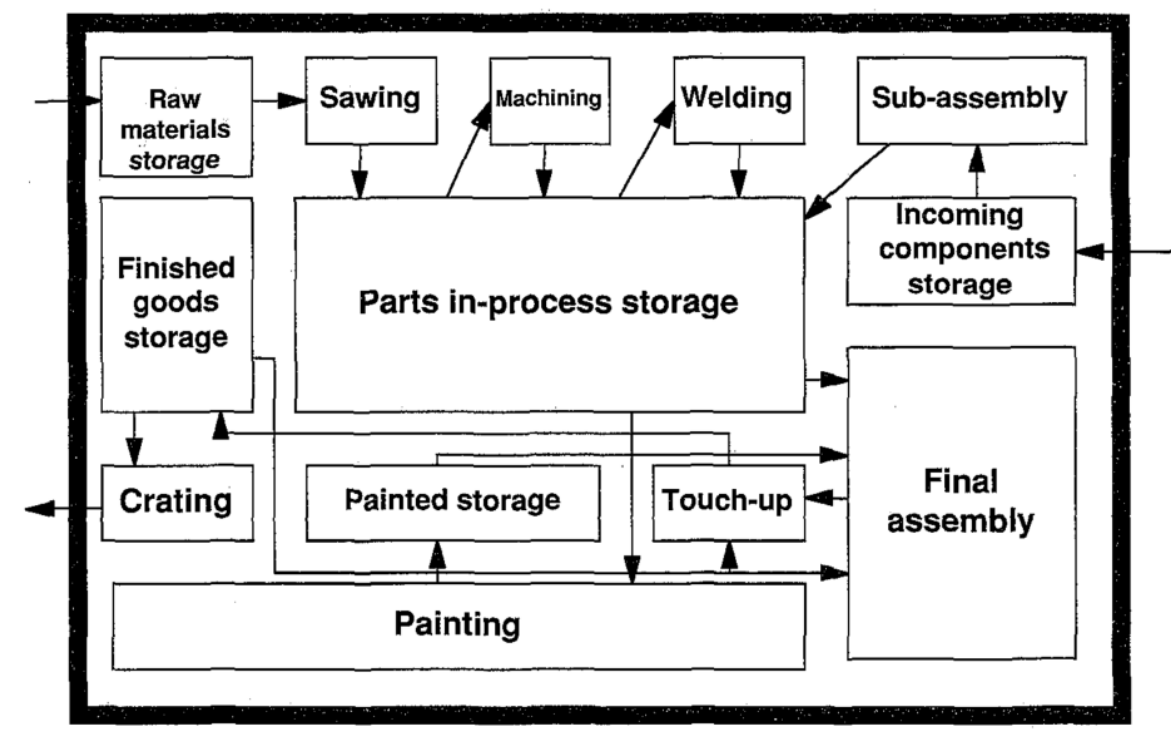

Figure 5: Example of a spaghetti diagram (adapted from Womack and Jones, 2003)

\section{Problems analysis and discussion of proposed improvements}

In this section is carried out the analysis of problems found in the Preh Company and a discussion of the proposals developed during this work. Thus, are shown the impacts of optimizing the Logistics Train, achieved by defining a fixed circuit and a standard time cycle (TC), normalizing the supply of materials and the organization of certain areas of the manufacturing area. Company Preh Portugal, founded in 1969 in Trofa, Portugal. This company belongs to the Preh Group, which is an international consortium emerged in 1919 in Bad Neustadt an der Saale (in Germany), accounting for about 4200 employees spread over Germany, Portugal, United States, Mexico, Romania and China.

Able to generate EUR 611 million in sales, this organization was responsible for developing the "PrehFunk", one of the first radio receivers all over the world.
Its Portuguese branch presents itself as an important reference in the automotive industry, laboring in the electrical components sector.

In the Preh Company, the absence of a fixed route to the Mizusumashi conducted to the need of standardizing and organizing the way it moves within the organization, as it was resulting in unpredictable and inefficient routes. With the objective of analyzing the resulting movements of the tasks with which it is responsible to interact, were prepared spaghetti diagrams. Each diagram corresponds to a Mizusumashi cycle and these were recorded over 520 days of study. The spaghetti diagram shown in Figure 6 is a result of overlapping all the work that was developed for this purpose.

The observation of this spaghetti diagram enables to identify:

- Regions most visited by Mizusumashi, either for need to access or preference for some responsible operator. 
The analysis of the density of the recorded flows is evident over the course indicated in Figure 6 below.

- Neglected regions by Mizusumashi where indicated as the ones where were made only sporadic passages throughout the working periods. With the attempt to shorten the maximum distances, the logistics operator ends up neglecting certain areas in favor of other considered more convenient ones. The circulation corridor that divides the machines 25 and 03 , are used only on few occasions, and this is the most notorious case in this spaghetti diagram.

- Inefficient and time-consuming paths, responsible for significant loss of time.

- Failure to comply with rules established by the organization prohibiting the circulation of Mizusumashi in certain areas such as Warehouse 1, in areas marked with yellow tape in Warehouse 3 or outside the yellow painted lines on the shopfloor.

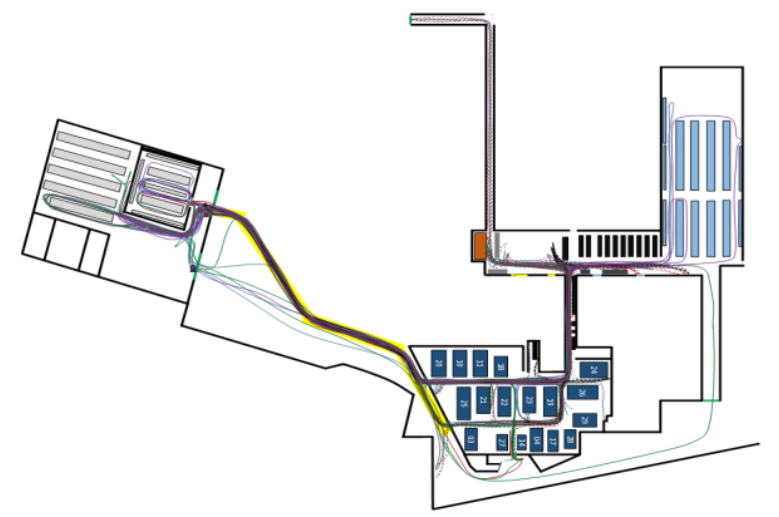

Figure 6: Initial spaghetti diagram

\section{Sequence diagrams}

In order to acquire a better understanding of how the Mizusumashi operates, it proved essential to analyze the activities it performs within the organization. For this purpose sequence diagrams were created, which were developed simultaneously with the spaghetti diagrams already mentioned.

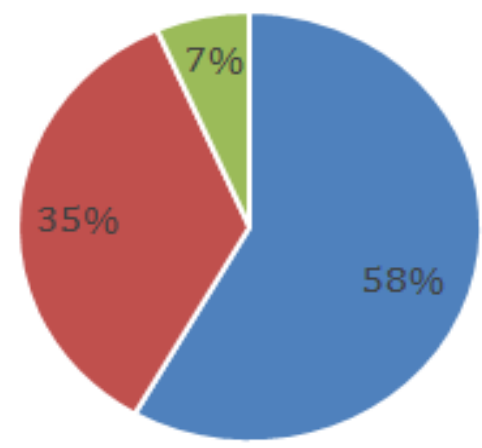

Figure 7: Mean time and percentage per activity. Operations: 58\%; Transport: 35\%; Waiting: $7 \%$

Based on measurements made during the diagrams created, for each type of activity (operations, transportations and waits), and the impact on the observed cycles.
The graph of Figure 8 summarizes the information presented in the sequence diagrams, representing time and the average percentage for the types of activities considered.

According to the graph, the average percentage of downtime activities is around $42 \%$, mainly due to the high values recorded in transport $(35 \%)$, which are the most obvious waste in this analysis.

\section{Irregular cycle times}

The analysis of sequence diagrams identifies considerable fluctuations in durations of registered cycles. The measurements made may be observed in the following graph (Figure 8):

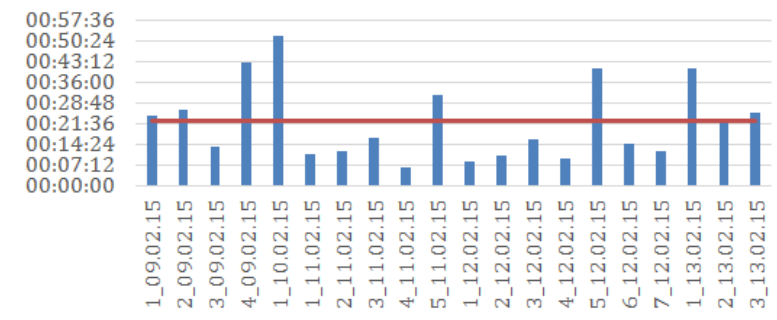

Figure 8: Time registered per cycle (CT)

The variability expressed through Figure 9 is mainly due to the lack of standardization in the way the Mizusumashi works. The lack of a fixed route and of a standard cycle time results in a logistics carried out by just one operator, which has to respond to orders as they are arriving. Therefore, the Mizusumashi passes through the production sections certain periods of the day that is completely overwhelmed with orders and others in which it is virtually unoccupied.

Increased number of transportations and movements

Despite being expectable and understandable that Mizusumashi spends some time on transactions - due to the requirement to meet the needs within the sections and to perform other duties that have been entrusted $35 \%$ in transport activities is a too high value for this type of waste.

The value of this percentage is justified by the fact of inefficient and time-consuming paths, spoiled by the lack of an established fixed circuit, and the need for extensive travel by foot caused by the reduced space available for free movement and the access limited to certain areas of the organization.

Increased waiting time

The standby time resulting from activities such as carriage changes, needs inquiries from operators, battery exchange, among others responsible for slowing down the normal operation of Mizusumashi represents an impact of about $7 \%$ in the average duration per cycle.

The amount related to this type of activity is essentially derived from the lack of mechanisms to simplify the request of raw materials and visual management of stock levels in sections, as well as the difficulty in 
maneuvering the logistics train when paired multiple carriages to transport different loads.

Increased time on Warehouse 3

According to the graph of Figure 8, operations corresponding to $58 \%$ of the average cycle time for registered Mizusumashi. From a careful analysis of the type of activity in question, it was found out that $46 \%$ of that is due just to the loading/ supply of materials in Warehouse 3, as illustrated by the graph in Figure 9.

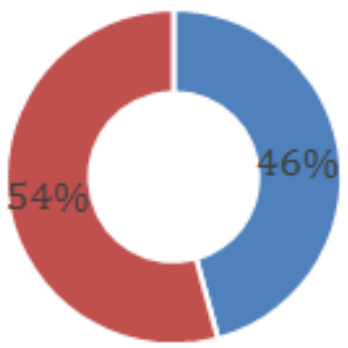

Figure 9: Mean time and percentage of operations in warehouse 3

Operations in Warehouse 3: 46\%; Other operations: $54 \%$

The value of $46 \%$, corresponding to the sharp average duration of operations in Warehouse 3, are usually a result of the difficulties experienced by the logistics operator to find the premises for storage of required raw materials.

Before the mentioned obstacle, the operator feels the need to ask for the cooperation of the managing operator of warehouse 3, which, based on their extensive experience, is usually able to indicate the position assigned to each material. When the operator cannot assist, either do to unavailability or ignorance, the Mizusumashi can choose to consult the lists of references displayed on the shelves of the supermarket of Plastic Injection, or access to data in the SAP system through a computer available on site (Figure 10).

\section{Improvement proposals}

This section resumes the main improvement proposals for resolving the previously identified problems. The solutions considered - developed based on information from the Gemba and suggestions submitted by employees - include the normalization of the Mizusumashi and the corresponding cycle time, along with the introduction of visual systems able to regulate the supply in the plastics injection and cutting production sections (supported by two excel-based applications designed to generate the consumption of different materials) and the corresponding whole reorganization of its production areas.

\section{Mizusumashi circuit}

The circuit proposed for Mizusumashi arises in order to standardize the way it moves within the manufacturing system.

Based on the analysis of the paths registered in spaghetti diagrams and lists of present activities in the sequence diagrams, the route presented in Figure 10 shows the proposal for the Mizusumashi to be coordinated by the logistics operator.

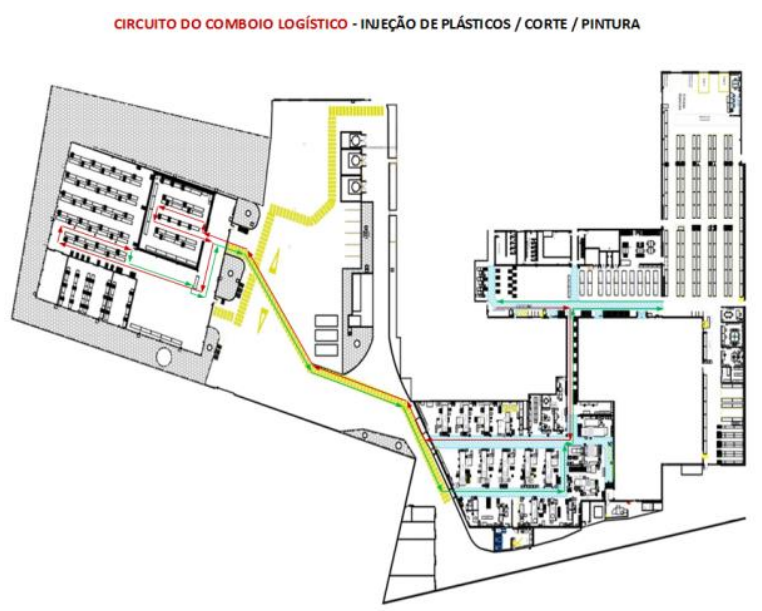

Figure 10: Circuit established for the Mizusumashi.

With the implementation of this proposal is ensured regular and equitable passage of Mizusumashi on the sections to supply - plastic injection, painting and cutting - at the same time it prevents the adoption of misleading paths, ineffective and more time consuming.

Standard cycle time

The amount of variability in the durations of the cycles analyzed in the elaborated graphs led to the need to establish a standard cycle time for Mizusumashi. Based on the average value calculated (22m and 29s) and given the wide range of job functions of the logistics operator - which includes tasks without predictable cadence, such as the request of material by the painting section, including equipment (such as gloves), delivery of orders approved by the Quality department, the supply of plastic Injection with auxiliary materials (rolls of tape and cling film, black plastic bags, etc.) and cleaning of the factory work space - it was estimated a standard cycle time of 45 minutes, in accordance with the operators involved.

The Cycle Time (CT) emerged in the order to convert the value of ValStd, which is a production time, in minutes, per 100 parts produced, to be converted in seconds per part. In order to obtain these values was applied the following expression:

$$
\text { Cycle Time }(C T)=\frac{\text { production time } \times 60}{100}[\text { sec } / \text { part }]
$$

Known CT values and Mizusumashi Cycle Time in minutes, the excel-based program is able to determine the amount of injected pieces for each reference in the setted time interval for the second parameter, performing at Qty.

The results produced are expressed through the following expression:

Quantity Produced $=\frac{\text { Mizusumashi Cycle Time }(\min ) \times 60}{\text { CT }}[$ unit $]$ 


\section{Fixed circuit and standard cycle time}

The definition of a fixed circuit to meet the logistics operator associated with the respective standard cycle time, allowed the regular and standardized Mizusumashi passage on the sections to supply in an efficient and productive way. Through the proposal developed could be avoided the adoption of unsuitable paths, as well as the occurrence of long periods of time without circulation through certain zones of the factory. The spaghetti diagram registered after normalization of the parameters considered can be seen in Figure 11, and measurements made during this work enabled to prove the stabilization of the CT.

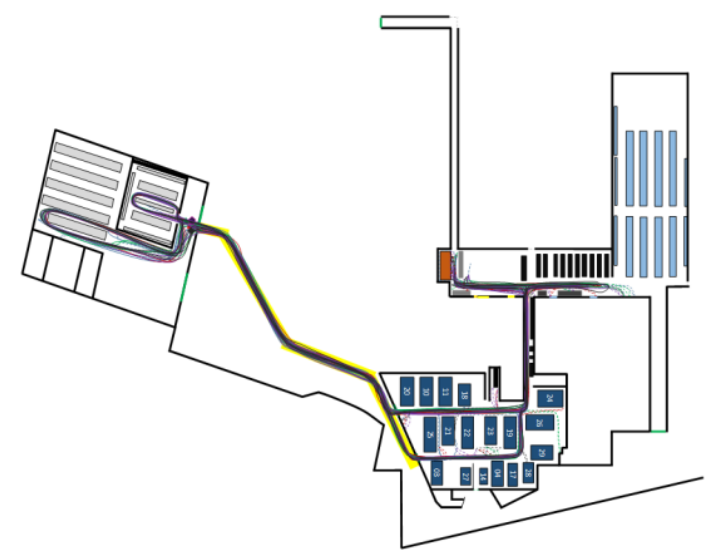

Figure 11: Spaghetti diagram after standardization.

\section{Normalization of materials distribution}

Normalization of the supply of materials ensures that it is performed equally for all Mizusumashi operators, thereby providing more robustness to this process.
The activity of the employees involved on the production section analysed was improved by the use of instructions based on a visual management system. Through this approach are considered all questions for avoiding any excessive and inconsistent supply, resulting in a more efficient behaviour of the operator and the Mizusumashi.

The mechanisms implemented enabled to reduce significantly the amount of accumulated materials in the plastic injection and cutting sections, without compromising production performance on these sections. Their levels of material stock were settled and stabilized in order to keep in the manufacturing zones just the minimum quantities of material necessary to meet the needs associated to ongoing production needs.

In addition, for reducing the amount of material deposited in the plastic injection, it is worth to emphasize the reduction of approximately $47 \%$ in the average time spent by Mizusumashi operations in Warehouse 3. This improvement resulted primarily from the implementation of visual mechanisms, such as kanban cards and record sheets applied inside the train, which inform the logistics operator on the storage location of the main materials to supply, thus preventing waste of time to consult the lists of references posted in the warehouse or by other operators locally on each production section.

\section{Improvement of the available factory space}

The removal of pellets in the plastic injection section and the optimization of space for placement of ESD medium and small boxes, enabled to release around $32 \mathrm{~m} 2$ in the production area (indicated in red on Figure $12)$.

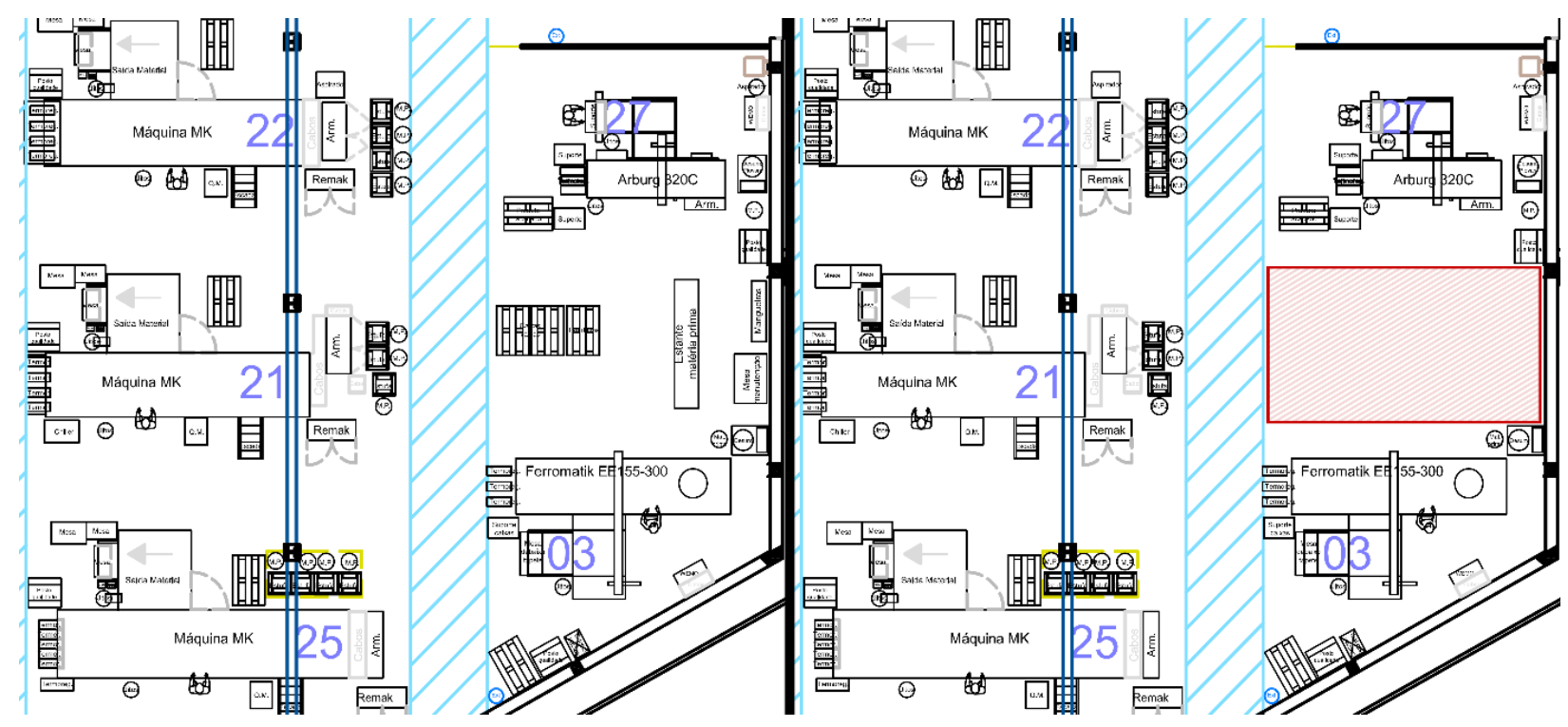

Figure 12: Extra space obtained in the production area. Triangle

In the current scenario the Company plans to introduce a new injection machine in the section, through the space made available by the improvements performed. 


\section{Conclusions}

This paper described a proposed application of lean approaches and techniques to implement improvements on a Portuguese Automotive Company.

Regarding some main problems identified in a preliminary diagnosing phase of this work, the application of lean production tools mentioned on this paper enabled to propose some effective suggestions for reaching relevant improvements on the Company for solving them. These actions include the implementation of a standard route and an associated cycle time, the standardization of the supply tasks based on visual systems, and the organization/ rationalization of the factory floor.

The implementation of these proposals of improvements resulted in a positive impact on the Company: the adjustment of Mizusumashi routes and the stabilization of its cycle time, the increased robustness of the supply process, the significant reduction in the quantities of materials stored in the plastic injection section (from $9,15 \%$ to $93,81 \%$ ), the substantial reduction in the time spent by the Mizusumashi in operations performed in the Warehouse $3(46,59 \%)$, and the increase of the available area in the factory floor $(32 \mathrm{~m} 2)$.

\section{Acknowledgment}

This work was supported by FCT "Fundação para a Ciência e a Tecnologia" under the program: PEst20152020.

\section{References}

[1] Alavi, S. (2003). Leaning the right way. Manufacturing Engineer, 82(3), 32-35.

[2] Chalice, R. (2007). Improving Healthcare Using Toyota Lean Production Methods: 46 Steps for Improvement: ASQ Quality Press.

[3] Dennis, P. (2005). Andy \& Me: Crisis and Transformation on the Lean Journey: Productivity Press.

[4] Di Pietro, L., Mugion, R. G., \& Renzi, M. F. (2013). An integrated approach between Lean and customer feedback tools: An empirical study in the public sector. Total Quality Management \& Business Excellence, 24(8), 899-917.

doi:http://dx.doi.org/10.1080/14783363.2013.791106. [5] Hines, P., \& Rich, N. (1997). The seven value stream mapping tools. International Journal of Operations \& Production Management, 17(1), 46-64.

[6] Hines, P., Found, P., Griffiths, G., \& Harrison, R. (2011). Staying Lean: Thriving, Not Just Surviving (2nd ed.). New York: Productivity Press.
[7] Imai, M. (2012). Gemba Kaizen: A Commonsense Approach to a Continuous Improvement Strategy (2 ed.): McGraw-Hill Education.

[8] Karim, M. A., Smith, A. J. R., Halgamuge, S. K., \& Islam, M. M. (2008). A comparative study of manufacturing practices and performance variables. International Journal of Production Economics, 112(2), 841-859. doi:10.1016/j.ijpe.2007.07.005

[9] Kerper, D. A. (2006). Lean Improvement Methodologies.

[10] Liff, S., \& Posey, P. A. (2004). Seeing is Believing: How the New Art of Visual Management Can Boost Performance Throughout Your Organization: AMACOM.

[11] Liker, J. K. (2004). The Toyota way: 14 management principles from the world's greatest manufacturer. New York: McGraw-Hill Professional.

[12] Liker, J. K., \& Meyer, D. (2006). The Toyota Way Fieldbook: McGraw-Hill Education.

[13] Marchetti, B. (2012). Rapidez e Agilidade: Aumento de Produtividade. Retrieved from http://blog.br.kaizen.com/2012/08/09/mizu/

[14] Pinto, J. P. (2008). Lean Thinking: Introdução ao pensamento magro: Comunidade Lean Thinking.

[15] Rawabdeh, I. A. (2005). A model for the assessment of waste in job shop environments. International Journal of Operations \& Production Management, 25(7-8), 800-822. doi:10.1108/01443570510608619

[16] Rother, M. (2009). Toyota Kata: Managing People for Improvement, Adaptiveness and Superior Results: McGraw Hill Professional.

[17] Sayer, N. J., \& Williams, B. (2007). Lean For Dummies: Wiley Publishing, Inc.

[18] Tapping, D. M. (2006). The Lean Office Pocket Guide XL: MCS Media, Inc.

[19] Van Scyoc, K. (2008). Process safety improvement-Quality and target zero. Journal of Hazardous Materials, 159(1), 42-48. doi:http://dx.doi.org/10.1016/j.jhazmat.2008.02.036

[20] Warnecke, H. J., \& Hüser, M. (1995). Lean production. International Journal of Production Economics, 41(1), 37-43.

[21] Womack, J. P., \& Jones, D. T. (2003). Lean Thinking: Banish Waste and Create Wealth in Your Corporation (2nd ed.). New York: Free Press.

[22] Womack, J. P., Jones, D. T., \& Roos, D. (1990). The Machine That Changed The World: The Story of Lean Production. New York: Rawson Associates. 
Copyright of Romanian Review Precision Mechanics, Optics \& Mecatronics is the property of Romanian Review Precision Mechanics, Optics \& Mecatronics and its content may not be copied or emailed to multiple sites or posted to a listserv without the copyright holder's express written permission. However, users may print, download, or email articles for individual use. 